\title{
Development of Tractor Operated Seed Ferti Drill-Cum-Weedicide Applicator
}

\author{
A. S. Ghadge*, A. S. Waghmode, K. B. Phalphale, S. H. Thakare and A. K. Kamble \\ Department of Farm Power and Machinery, Dr. PDKV Akola, India \\ *Corresponding author
}

\section{Keywords}

Design of frame, Weedicide tank, Supporting frame of HTP pump, Design length of belt, Diameter of pulley, Component, specifications

Article Info

Accepted: 08 January 2020 Available Online: 10 February 2020

\section{A B S T R A C T}

Farm mechanization is the application of engineering technology in agricultural operations to do a job in a better way to improve productivity. This includes development, application and management of all mechanical aids for field production, water control, material handling, storing and processing. Tractor operated seed ferti drill-cum-weedicide applicator was developed and evaluated techno-economic feasibility in the field at Central Demonstration Farm, Wani-Rambhapur Dr. PDKV Akola. During sowing season of the crop, there is an acute shortage of labour, which causes delay in sowing of crop which ultimately results in a reduction of yield. Sowing or drilling the seed is one of the important operations for the crop. After sowing of the seed in field simultaneously weed also grow. Weeds are the most serious problem to the farmers which create obstruction for crop growth and compete with the crop. Application of the weedicide simultaneously along with sowing will minimize the problem and it will save complete operation of spraying weedicide.

\section{Introduction}

Development of tractor operated seed ferti drill-cum-weedicide applicator can fulfill mechanization gap between the spraying and sowing operation at the faster rate. Tractor operated weedicide applicator has given the good result. This shows, there is an urgent need to introduce this type of implement. Development tractor operated seed ferti drillcum-weedicide applicator is the need of our today's farming to reduce the drudgery in the operation with saving time and labor, to do work effectively and covering more area with minimum time.

\section{Necessity}

In India, diverse farm mechanization scenario prevails in the country due to varied size of the farm holdings and socio-economic disparities. In the trend of growth of power 
operated machinery used by farmers, Seed drill is used for sowing and drilling of the seed in field. Before the sowing of the seed into the field, farmer uses pre emergence application of weedicide solution in the field. Using manual sprayer, it is an important application which controls the weed into the field.

In India sowing is done by using of the tractor operated seed drills. After sowing, weedicide application is done manually but it requires more labour and time. Tractor operated seed ferti drill-cum-weedicide applicator helps in timeless operation and it does the sowing and weedicide application process at same time. The seed cum ferti drill were already developed and was available in market was selected and weedicide applicator was decided to develop.

\section{Scope}

Many of the farmers cannot afford different types of the implement used in the agricultural operations it is also like ploughing, harrowing, cultivator, weedicide sprayer etc. and it is also difficult to purchase for small and marginal farmers due to the high cost of the implement. Now a day's sowing operation done by the use of the draft animals in villages is also done by the use of tractor operated seed drills. Also sowing operation is done for the use of seed cum fertilizer drill. After some weeks of crop growth simultaneously weed is also grow in the field. For controlling the weed, weedicide application with the help manually operated sprayer on it for reducing the weed is accomplished. It requires more labour, more time, and it is costly, also for reducing this problem development of tractor operated seed ferti drill-cum-weedicide applicator was essential which saves time, cost of production, and labour by doing all operations in single stage.

\section{Design considerations}

\section{Agronomical requirements}

A machine was designed by keeping its spacing and number of rows to be sprayed.

\section{Physical and economic considerations}

Machine should be simple in design and it should be easy to operate.

Cost of the machine should be low.

It should be easily repairable by farmer or village artisans.

The total power requirement should not exceed the power available from available tractors (45 hp).

Machine should be light in weight

\section{Development of tractor operated seed ferti drill-cum-weedicide applicator}

\section{Design of frame for lifting the 200 lit tank}

Taking into consideration the weight of tank and liquid to be filled inside tank, the frame was designed to sustain the weight. The specification of the frame is $1600 \times 580 \times 610$ $\mathrm{mm}$ with thickness $5 \mathrm{~mm} \mathrm{~m}$. s. angle iron were used to develop a frame as shown in Fig. no. 3.1. Side support was also given taking into consideration the dynamic weight of weedicide in the tank.

The bending equation is given by.

$\frac{M}{I}=\frac{\sigma}{y}=\frac{E}{R}$

Where,

$M=$ Bending moment acting at the given section

$\sigma=$ Bending stress,

$I=$ Moment of inertia of the cross-section about the neutral axis, 
$y=$ Distance from the neutral axis to the extreme end,

$E=$ Young's modulus of the material of the angle, and

$R=$ Radius of curvature of the angle.

Factor of safety $=\frac{\text { maximum stress }}{\text { working stress }}$

Bending moment $(\mathrm{M})=\mathrm{W} \times \mathrm{L}$

Where,

$\mathrm{W}=$ Weight, $\mathrm{N}$

$\mathrm{L}=$ Length, $\mathrm{mm}$

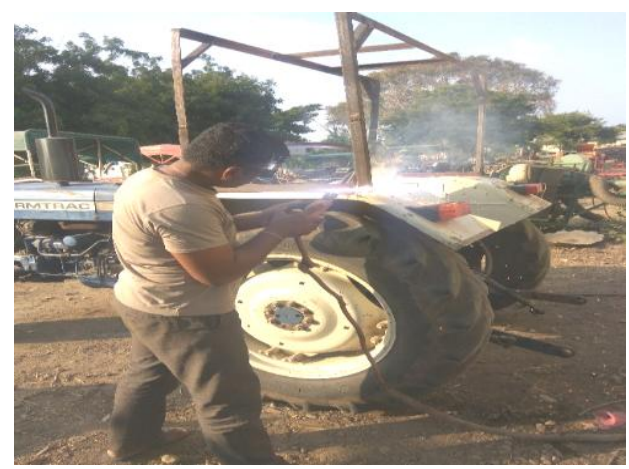

Fig.1 Frame of weedicide tank

\section{Weedicide tank}

The HDPE tank of capacity 200 litter size was purchased from the market for storing the weedicide. The purchase prize of the weedicide tank from market was Rs.1800. Dimension of the weedicide tank has length $860 \mathrm{~mm}$, width $640 \mathrm{~mm}$, and height $440 \mathrm{~mm}$. Upper side of tank has one hole for overflow of the weedicide from HTP pump having the diameter of the hole as $20 \mathrm{~mm}$ in Fig.

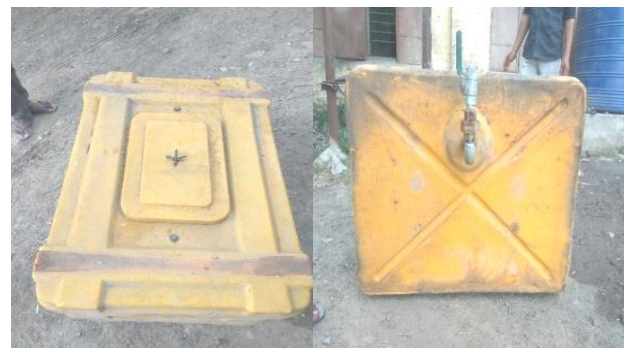

Fig.2 Weedicide tank

\section{Supporting Frame of HTP Pump}

The supporting frame of HTP pump was made up of cast iron. Specifications of supporting frame are height is $860 \mathrm{~mm}$ and width of frame $270 \mathrm{~mm}$. Total height of frame is $930 \mathrm{~mm}$ Fig.

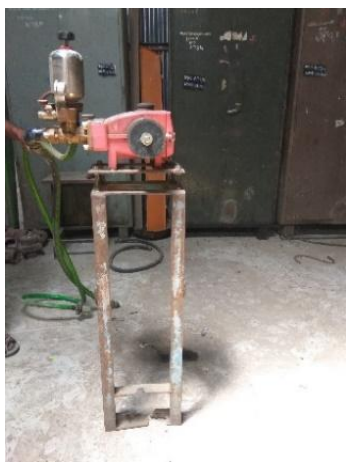

Fig.3 Supporting frame of HTP pump

\section{Length of belt}

Two belts were used to transmit the power from PTO to HTP pump i.e. A-87 type belt is used. The belt length was $2400 \mathrm{~mm}$ and thickness was $20 \mathrm{~m}$

Design length of the belt

Consider,

$r_{1}$ and $r_{2}=$ Radii of the larger and smaller pulleys,

$\mathrm{x}=$ Distance between the centers of two pulley $\quad \mathrm{L}=$ Total length of the be

$\mathrm{d}_{1}$ and $\mathrm{d}_{2}=$ Diameter of larger and smaller pulley

Length of belt $=$

$$
\frac{\pi}{2}(d 1+d 2)+2 x+\frac{(d 1-d 2)^{2}}{4 x}
$$

\section{Diameter of pulley}

The pulleys are used to transmit power from one shaft to another by means of flat belts, Vbelts or ropes. Diameter of HTP pump is 110 $\mathrm{mm}$ and diameter of PTO pulley is $170 \mathrm{~mm}$. 


\section{Design of pulley}

We know that the centrifugal stress induced in the rim of the pulley,

$\sigma t=\rho \cdot \mathrm{V}^{2}$

where,

$\rho=$ Density of the rim material

$=7200 \mathrm{~kg} / \mathrm{m}^{3}$ for cast iron

$\mathrm{V}^{2}=$ Velocity of the rim

$=\pi \mathrm{DN} / 60$, $\mathrm{D}$ being the diameter of pulley and

$\mathrm{N}$ is speed of the pulley.

\section{Seed ferti drill}

\section{Functional components of the machine}

1. Main frame

2. Tynes

3. Furrow openers

4. Ground wheel

5. Hitching unit

6. Seed cum fertilizer box

7. Seed tube

8. Drives for metering device

9. Weedicide sprayer unit

10. Seed covering blade

11. HTP pump supporting Frame

12. Tank supporting frame

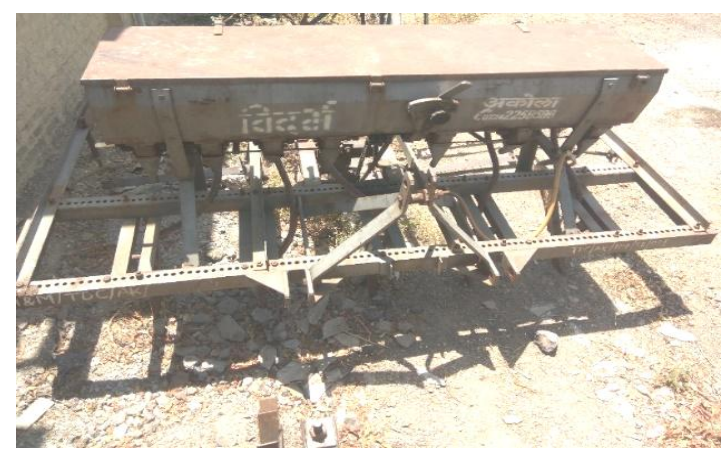

Fig.4 Main frame of seed drill

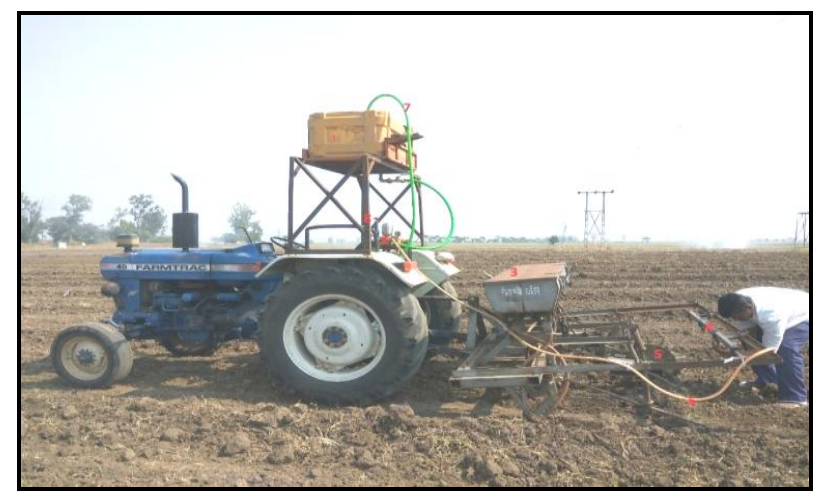

Fig.5 Tractor operated seed ferti drill-cumweedicide applicator

1.Tank 2. HTP Pump 3. Seed cum fertilizer box 4. Nozzle frame 5. Ground wheel 6 . Weedicide pipe 7. Overflow pipe 8. Tank supporting frame

\section{Frame for nozzles}

The frame nozzlewas made from the m.s angle $40 \times 50 \times 5 \mathrm{~mm}$. Total length of the nozzle frame was $2970 \mathrm{~mm}$. Distance between the two nozzle is $450-550 \mathrm{~mm}$. The height of the nozzle frame from the ground is $500 \mathrm{~mm}$.

\section{Weedicide applicator}

\section{Functional components of sprayer}

1. Weedicide tank

2. HTP piston pump

3. Supporting frame of HTP pump

4. Pulley and belt

5. Hoses and nozzle

6. Supporting frame of weedicide tank

\section{HTP Pump}

HTP, horizontal Triplex piston power sprayer unit, developing $28 \mathrm{~kg} / \mathrm{cm}^{2}$ pressure and giving free discharge of $24 \mathrm{lpm}$ at $950 \mathrm{rpm}$, supplied with pulley, pressure vessel, pressure gauge. By-pass cum pressure regulator valve (CVA) was used as shown in Fig. 
Table.1 Specifications of weedicide applicator

\begin{tabular}{|l|l|l|}
\hline Sr. No & Particulars & Sprayers specifications \\
\hline $\mathbf{1}$ & HTP pump & Dual piston, Aspee, PS-26 \\
\hline $\mathbf{2}$ & Tank capacity, lit & $\mathbf{2 0 0}$ \\
\hline $\mathbf{3}$ & Power transmission to pump & Tractor PTO \\
\hline $\mathbf{4}$ & Hose pipes & Nylon material \\
\hline $\mathbf{5}$ & Nozzles & Hollow cone nozzle \\
\hline $\mathbf{6}$ & No of nozzles & $\mathbf{4}$ \\
\hline $\mathbf{7}$ & Nozzle to nozzle distance, $\mathrm{mm}$ & $\mathbf{4 5 0}$ \\
\hline $\mathbf{8}$ & Nozzle discharge, $\mathrm{l} / \mathrm{m}$ & $\mathbf{1 . 9 8}$ \\
\hline $\mathbf{9}$ & Nozzle pressure, $\mathrm{kg} / \mathrm{cm}^{2}$ & $\mathbf{2 . 5}$ \\
\hline $\mathbf{1 0}$ & Frame Fittings & Nuts \\
\hline $\mathbf{1 1}$ & Max height of nozzle from ground, $\mathbf{m m}$ & $\mathbf{9 0 0 - 1 2 0 0}$ \\
\hline
\end{tabular}

Table.2 Specifications HTP piston pump

\begin{tabular}{|l|l|}
\hline Model & AS-26 \\
\hline Dry Weight (without pully \& oil) kgs & 9.6 \\
\hline Suction capacity (1/m) & 24 \\
\hline Pump RPM & 950 \\
\hline Pressure kg/cm² (max) & 28 \\
\hline Pressure kg/cm (working) & 14 \\
\hline Power required, HP & 3 \\
\hline Engine (Ps.) & 3.5 \\
\hline L x W x H ,mm & 320 x 240 x 395 \\
\hline Pump material & Brass \\
\hline
\end{tabular}
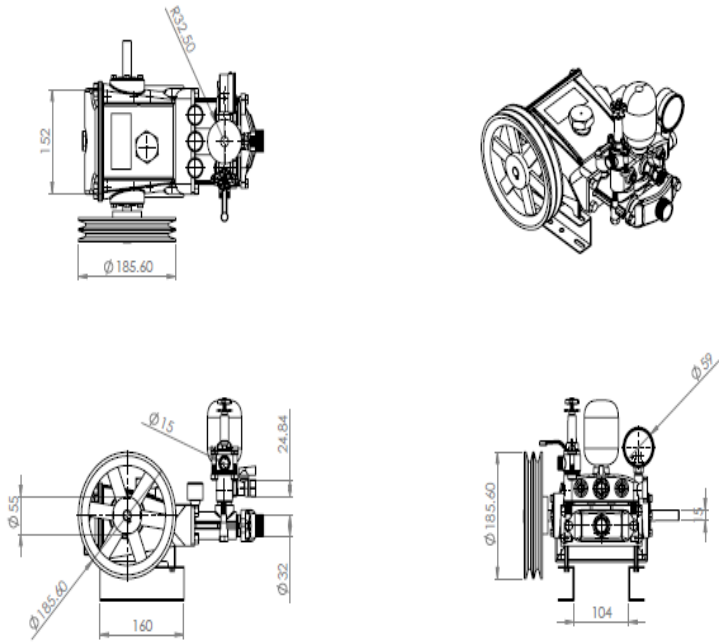

Fig. Schematic view of HTP Pump 


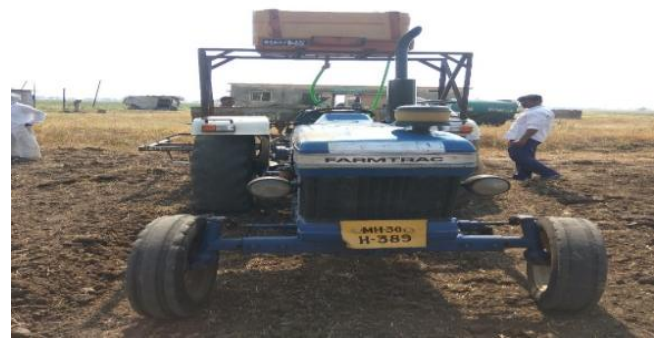

A) Front view

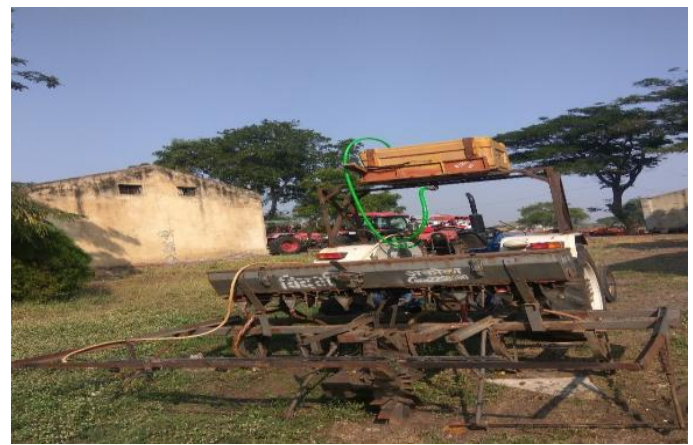

b) Back view

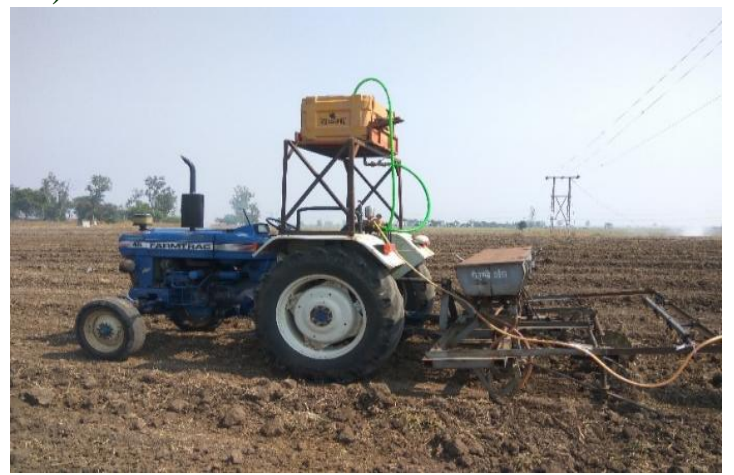

b) Side view

Summary and conclusions are as follows:

During operation of spraying season, there is an acute shortage of labour, which causes a delay in spraying on crop which ultimately results in a reduction of crop. The traditionally method and manually spraying were used by the farmers but these was timeconsuming processes. There was a need of high capacity machine for weedicide application.

\section{References}

Achutha M.V. Sharath Chandra. N Nataraj.G. K (2016) Concept Design and Analysis of Multipurpose Farm Equipment International Journal of Innovative Research in Advanced Engineering (IJIRAE) ISSN: 2349-2763 (02) 3 .

Gautam A. S.V. Jogdand and Vinay K. N. (2013); design development of Animal drawn multipurpose tool carrier suitable for nondescript breed of bullock of Chhattisgarh International Journal of Agricultural Engineering; 6 (1): 142-145.

Gupta, C.P. and Unadi, A. (1994) Development of two-wheel tractor operated seed cum fertilizer drill. Agricultural Mechanization in Asia, Africa and Latin America, 25(1):25-2.

Gupta, R.A., Pund, S.R. and Patel, B.P. (2003). Design and Development of Bullock Drawn Traction Sprayer. Agricultural Mechanization in Asia Africa and Latin America., 2: 33-37.

Kannan, K. Esakkiraja, S. Thimmarayan, (2014). Design modifications in multipurpose sowing machine international journal of research in aeronautical and mechanical engineering. 2(1).

Shukla, L. N., Sidhu, H. S. and Bector, V. (2003) Development of commercial prototype of direct drilling machine with notched-double disk furrow openers. Journal of Agricultural Engineering

Singh S K, Singh S, Dixit A K and Khurana R (2010) Development and field evaluation of tractor mounted air assisted sprayer for cotton. AMA 41(4):49-54.

Verma A. and Prabhat K. G. (2014) Development and evaluation of cultivator cum seed drill. Eco. Env. \& Cons. 21(3):2015; pp. (13591364)

Vatsa, D.K and Sukhbir Singh (2010). Sowing methods with different seed drills for mechanizing mountain farming. Agricultural Mechanization in Asia, Africa and Latin America. 41(1): 51-54. 


\section{How to cite this article:}

Ghadge, A. S., A. S. Waghmode, K. B. Phalphale, S. H. Thakare and Kamble, A. K. 2020. Development of Tractor Operated Seed Ferti Drill-Cum-Weedicide Applicator. Int.J.Curr.Microbiol.App.Sci. 9(02): 634-640. doi: https://doi.org/10.20546/ijcmas.2020.902.078 